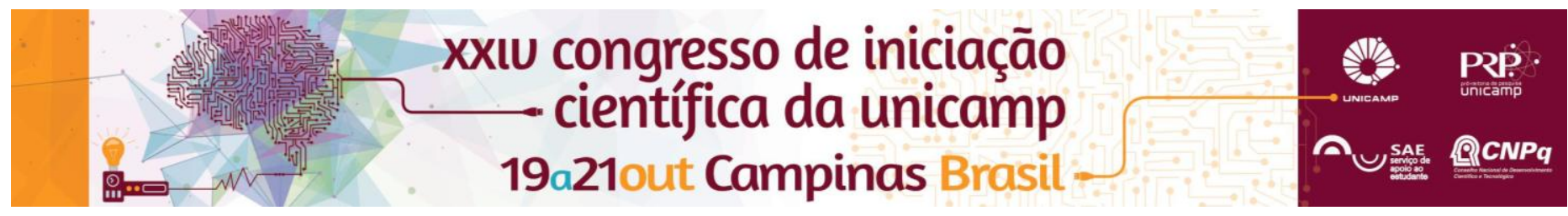

\title{
Avaliação da Expressão de Proteínas Relacionadas à Lipogênese e Glicólise em Melanomas Nasais e de Cavidade Oral
}

\author{
Edson Robles Castilla Filho*, Harim Tavares dos Santos, Alicia Rumayor Piña, Erika Egal, Fernanda V. Mariano, \\ Albina Altemani
}

\section{Resumo}

Os melanomas mucosos de cabeça e pescoço são tumores potencialmente agressivos, raros e pouco estudados pelos profissionais de saúde. Quando diagnosticados já se encontram em estágios avançados, levando a altas taxas de mortalidade. Este estudo visa esclarecer como certas vias metabólicas (lipogênese e glicólise) podem auxiliar na sobrevivência e proliferação das células tumorais, estabelecendo possíveis alvos terapêuticos.

\section{Palavras-chave:}

Melanoma, Lipogênese, Glicólise.

\section{Introdução}

Melanoma é um tumor potencialmente agressivo de origem melanocítica. O melanoma mucoso primário da cabeça e pescoço representa menos de $1 \%$ de todos os melanomas. É reconhecido que alterações metabólicas da célula cancerosa, como aumento da lipogênese e glicólise, conferem-lhe vantagens na sobrevivência. $O$ objetivo desse trabalho foi avaliar e correlacionar a expressão imunohistoquímica de proteínas relacionadas à lipogênese, glicólise e proliferação celular em melanomas primários de boca e cavidade nasal.

\section{Resultados e Discussão}

No total, 14 casos de melanomas primários de cavidade sinonasal e 10 de melanomas orais foram imunohistoquimicamente avaliados através da expressão das seguintes proteínas: adipophilin (lipogênese), GLUT1 (glicogênese) e Ki-67 (proliferação celular). O teste de Mann-Whitney foi usado para comparação das variáveis numéricas entre os grupos.

A expressão de adipophilin foi significativamente maior $(p=0,0488)$ nos melanomas sinonasais, enquanto que a expressão de GLUT-1 não mostrou diferença significante entre os dois grupos $(p=0,634)$. Em relação à proliferação celular, a expressão de Ki-67 foi significantemente $(p=0,0051)$ maior nos melanomas orais.
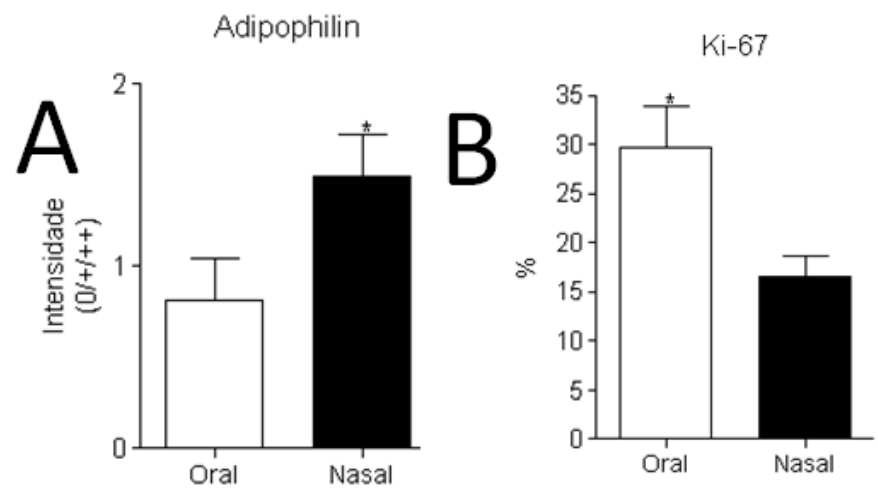

Figura 1- Expressão de adipophilin e Ki-67 foi significativamente maior nos melanomas nasais $(A)$ e orais $(\mathrm{B})$, respectivamente.

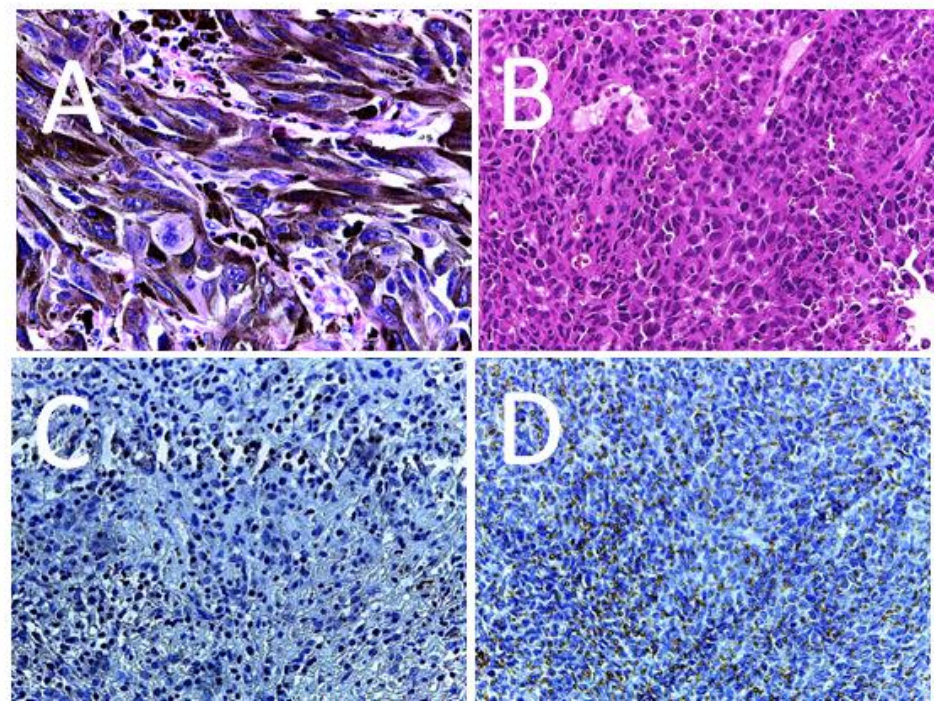

Figura 2- A - Melanoma composto por células fusiformes malignas ricas em melanina. B - Melanoma amelanótico apresentando células epiteliódes e plasmocitóides. C Escassas gotas lipídicas no melanoma oral. DQuantidade significativa de gotas lipídicas no melanoma nasal. (A - 400x, B - 200x - HE; C, D - 100x Imunoperoxidase)

\section{Conclusões}

Concluindo, a lipogênese é provavelmente uma importante via metabólica nos melanomas sinonasais. Como a proliferação celular é conhecidamente estimuladora de lipogênese, nos melanomas sinonasais há possivelmente outros fatores indutores de lipogênese que necessitam maiores estudos.

1-Brown DC, Gatter KC. Monoclonal antibody Ki-67: its use in histopathology. Histopathology. 1990; 17(6):489-503.

2-Ducharme NA, Bickel PE.Lipid droplets in lipogenesis and lipolysis. Endocrinology. 2008; 149(3): 942-9.

3-Hanahan D, Weinberg RA. Hallmarks of cancer: the next generation. Cell. 2011; 144(5):646-74.

4- Pfister DG, Ang KK, Brizel DM, et al. Mucosal melanoma of the head and neck. JNCCN: J Natl Compr Cancer Netw. 2012; 10: 320-38 